\title{
Understanding the relationship between ICT and knowledge sharing using structural equation modeling: A study from Indian milk co-operatives
}

\author{
Vangala Ram Naresh Kumar \\ Received: 01 November 2020 / Accepted: 28 Junuary 2021 / Published online: 07 June 2021 \\ (c) Indian Dairy Association (India) 2021
}

\begin{abstract}
The objective of this paper is to find out the relationship between information and communication technology (ICT) and knowledge sharing (KS) process in Indian Milk Cooperatives. This study uses a quantitative approach as an instrument to collect data from the questionnaire. A total of 114 samples were collected from two different milk co-operatives in India. The data obtained were analyzed and tested the hypothesis by using structural equation modeling (SEM). The result shows that ICT has a significant influence on KS in respondent milk cooperatives. The results of the study can serve as a guide to managers of the co-operatives in designing and ascertain the direction of ICT for effective KS practices.
\end{abstract}

Keywords:Information and communication technology, Knowledge management, Knowledge sharing, Milk cooperatives, Structural equation modeling

\section{Introduction}

Indian agriculture and allied fields are currently facing various challenges like climate change, declining water availability, degradation of land, shrinking land availability, the high cost of cultivation, environmental degradation, poverty and inaccessibility to modern technology, diminishing the availability of agricultural labor and farmers' reduced interest in agriculture (Kothari and Kameswari, 2019). The National Commission on Farmers has drawn attention to the knowledge deficit that constrains the agricultural productivity, which highlights the failure of public extension system and the inability of extension workers to enrich the farmers with knowledge of new technologies (Kale et al. 2015) that can enable them to be more productive. It has been widely recognized that the transfer of relevant knowledge plays an important role in agriculture growth and its productivity. Transfer of relevant knowledge to small

Vangala Ram Naresh Kumar $(\varangle)$

Department Dairy Business Management,

College of Dairy Technology, Kamareddy, Telangana

P.V. Narsimha Rao Telangana Veterinary University,

Email: ramnaresh4u@gmail.com and marginal farmers can help them to improve their yields and get better market prices (Patil et al. 2011; Kukreja et al. 2013).

Knowledge has become a valuable asset and key resource for improving an organization's performance (Karadsheh et al. 2009). Many organizations are exploring the field of knowledge management (KM) to improve their performance and sustain themselves in the competitive world (Yew Wong, 2005). Knowledge sharing (KS) is considered as the core process of KM since one of the main goals and objectives of KM is to promote the sharing of knowledge (Chua, 2004). It is processed in which sharing of knowledge takes place among individuals and or groups in the organization, thereby promoting learning and creation of new knowledge. Transfer of knowledge can be both in the horizontal and/or vertical directions. Horizontal knowledge transfer takes place between the employees in the organizations and vertical knowledge transfer takes place between organizations.

Information and communication technology (ICT) can make more competitive by providing affordable, relevant, searchable, and upto-date information service to farmers (Patil et al. 2011). Initiatives of ICTs in the livestock sector had helped the extension professionals an opportunity to produce customized extension material that met the real needs of the farmer. For example, in the livestock sector, Smallholder Dairy Tool Box (SDTB) which has been developed by the International Livestock Research Institute (ILRI) and International Crop Research Institute for Semi-Arid Tropics (ICRISAT). It is an ICT based application which contains simple decision support tools, as well as a broad range of modular information that can be easily accessed and compiled to form customized fact-sheets, or other extension materials, on a wide range of dairy-related topics for the farmers and extension officers (Thirunavukkarasu et al. 2008). Dairy information system kiosks (DISK), an ICT project develop by Anand Milk Union Ltd (AMUL), Gujarat with the support of Indian Institute of Management, Ahmedabad (IIMA). This DISK enables horizontal networking of all milk producing cooperative societies and vertical networking with district-level milk unions and state-level federations with the Internet connectivity. The district dairy portal will assist the transactional and information needs of co-operative staff, members (farmers), and other stakeholders (Rao, 2010). 
In the literature, many authors focused on the importance or impact of ICT in the dairy sector. For example, the advantages of ICT to provide effective delivery of information related to animal health care and production to the end-users. By providing a simplified version of information (related to animal husbandry technology) through cyber extension with text and multi-media in local languages had proven to be a cost-effective and powerful tool in building up the capacities of the farmers (Sasidhar et al. 2006). A study was conducted in Rajasthan, India to measure the attitude of livestock farmers' towards the usage of ICT in extension services as a source of information delivery (Rajoria et al. 2018). There have been very limited studies on the KS process at the organizational level and still fewer on the relationship between ICT and KS at the milk co-operative level in the Indian context. In this paper, we are trying to address this need, i.e., studying the relationship between ICT and the KS process in Indian Milk Co-operatives by using structural equation modeling (SEM) technique.

\section{Materials and Methods}

The main objective of this study is to understand the effect of ICT on the KS process in milk co-operative

Hypothesis (H1): ICT has a significant and direct effect on knowledge sharing in milk co-operatives.

Table 1 Items used for measuring research constructs
A quantitative research approach was used to test the research hypothesis. For the quantitative method, we developed a questionnaire using prior measurements corresponding to each variable reported in the literature. Since there are very few studies reported in the literature in the context of Indian agricultural organizations, in general, and Indian milk co-operatives in particular; the parameters used in other kinds of organizations were adopted in this study. The questions in the questionnaires were suitably modified to make them more relevant/appropriate for milk co-operatives.

A set questionnaire was designed and used to determine the relationship between $\mathrm{ICT}$ and $\mathrm{KS}$. The questionnaire was developed using earlier measurements corresponding to each variable which was derived from the literature (Siong et al. 2006; Lee et al. 2007). Each variable (related to ICT and KS) was addressed through multiple items in the questionnaire to increase the reliability of responses. Each item was based on a five-point Likert scale from "strongly disagree" to "strongly agree" (Albaum, 1997). Table 1 presents the items used to measure research constructs (ICT and KS).

\section{Data collection}

Muluknoor Women's Cooperative Dairy located at Karimnagar, Telangana, and Mehsana District Co-operative Milk Producers' Union Ltd located at Mehsana, Gujarat were selected. These Information and Communication Technology

ICT1 Our organization has ICT infrastructure (like computer, networks) for managing all kinds of documents on agriculture knowledge

ICT2 ICT infrastructure (like computers, software, networks) are easy to use for uploading, searching and retrieving agriculture knowledge

ICT3 I use ICT tools (like computers, emails, telephones, mobile) to communicate within the organization

ICT4 I routinely utilize ICT tools (like computers, emails, telephones, mobile) to access agriculture knowledge from outside organizations

ICT5 We use ICT tools (like computers, emails, telephones, mobile) for sharing agriculture knowledge with farm communities

ICT6 We use computers for storing agriculture knowledge

ICT7 We use the Internet and Intranet to access agriculture knowledge repository Knowledge Sharing

KS1 Periodical annual reports/success stories are made to share with all organization members

KS2 Periodical meetings/workshops/seminars are held to share best practices, new technology in agriculture

KS3 Farm communities are willing to share their experience and knowledge

KS4 Farm communities are willing to share their experience and knowledge with experts group

KS5 We share our field experience with a peer group in the organization

KS6 We use ICT tools like mobile, audio and video conference, the Internet for sharing agriculture knowledge

KS7 The organization encourages the employee to share their knowledge with peer groups and others

KS8 The organization has resources centers, community hall, and forums for sharing agriculture knowledge

KS9 I believe that sharing agriculture knowledge across groups will yield high benefit 
organizations were selected for this study as they exhibited a keen interest in mobilization and disseminating knowledge to the farm communities using ICT. Before running the actual survey in milk cooperatives, the questionnaire had gone through a pilot test, to ensure the objectives of the questionnaire were clear and to ensure content validity.

Unit of analysis in this study were middle-level managers, veterinary doctors, agriculture extension officers, project coordinators, cluster in-charge or supervisor, and field workers/operators. These people were surveyed because they play a key role in agricultural knowledge. These people were positioned at the intersection of both vertical and horizontal flow of knowledge. Therefore, they could synthesize the tacit knowledge of both top (scientist group) and bottom (farmer group) level, convert them into explicit knowledge, and incorporate the same into the organizational knowledge repository. There is no prior personal or formal relationship between researchers and interviewees or the organization as a whole. This allowed for triangulation and also helped to validate data interpretation and findings (Venkitachalam et al. 2014).

The questions were well-structured, understandable and were developed in four languages namely English, Hindi, Gujarati, and Telugu keeping in the mind the geographical locations and the composition of people working in milk co-operatives that were the part of the study.

\section{Results and Discussion}

A total of 114 respondents were covered through the questionnaire from the two co-operatives. Data were collected during their weekly and monthly meetings in the organization. During the meetings, questionnaires were distributed to participants and they were asked to fill the form. Before filling the form, the objectives of the research and questionnaire were explained to them. Data screening was done to ensure the data were clean and ready for further statistical analyses. During the data screening process, seven respondents were dropped due to unengaged responses. Therefore, the sample size for this study is 107 . Table 2 summarizes the demographic profile of respondents. The majority of the respondents have a bachelor's degree $(55.1 \%)$. From the perspective of designation, $65.4 \%$ field incharges/supervisors, $15.9 \%$ program managers, and veterinary doctors, and $2.8 \%$ managers. Furthermore, the majority of the respondents $(32.7 \%)$ had 6-10 years of experience in dairying.

\section{Reliability and validity test}

Reliability and validity tests were performed on 16 items that measure the components of both dependent (KS) and independent variables (ICT). Cronbach's alpha, formula is one of the most commonly used techniques to assess the reliability of the items (Sekaran et al. 2016). It suggests that as a rule of thumb, a Cronbach's alpha value of greater than or equal to 0.7 is required to satisfy the reliability (Hair et al. 2006). Referring to Table 3, this condition has been satisfied for both constructs ICT and KS.

Discriminant validity is used to test construct validity. It has been used because each construct was measured by multiple items. Factor analysis with varimax rotation is used to check discriminant validity.

The Kaiser-Meyer-Olkin (KMO) and Bartlett's measures of sampling adequacy were also computed for comparing the magnitudes of the observed correlation coefficients to the magnitudes of the partial correlation coefficients. The KMO value of greater than 0.5 indicates that factor analysis of the construct was good (Chadha et al. 2014).

Table 2 Demography profile of respondents

\begin{tabular}{lll}
\hline Sample characteristics & Frequency $(\mathrm{n}=107)$ & Percent $(\%)$ \\
\hline Male & Gender & 52.3 \\
Female & 56 & 47.7 \\
& 51 & 29.9 \\
High School & Education & 55.1 \\
Bachelor Degree & 32 & 15.0 \\
Master's Degree & 59 & 2.8 \\
& 16 & 15.9 \\
Managers & Working position of respondents & 15.9 \\
Program managers & 3 & 65.4 \\
Veterinary doctors & 17 & \\
Field in-charge/Supervisor & 17 & 23.4 \\
& 70 & 32.7 \\
$0-5$ years & Experiences of respondents & 30.8 \\
$6-10$ years & 25 & 13.1 \\
$11-20$ years & 35 & \\
Above 20 years & 33 & \\
\hline
\end{tabular}


Fig. 1 Simulation model for the relationship between ICT and KS

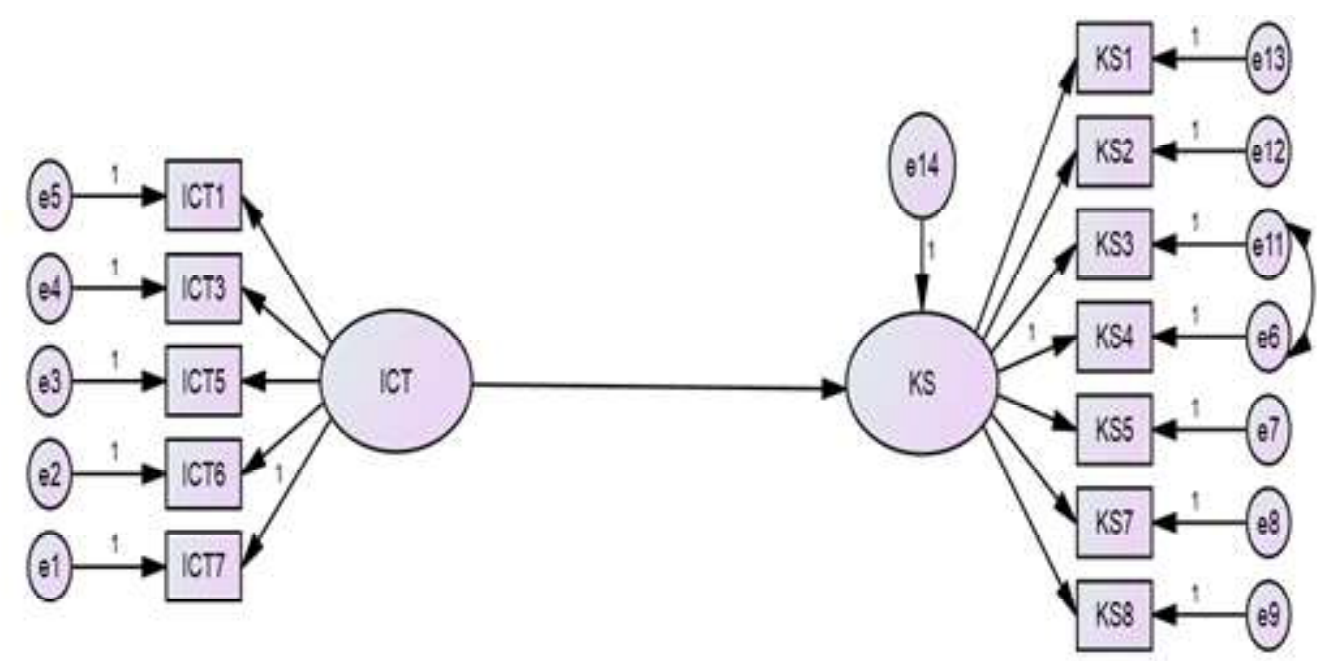

Table 3 Result of reliability and validity

\begin{tabular}{|c|c|c|c|c|c|}
\hline Constructs & $\begin{array}{l}\text { No. of } \\
\text { items }\end{array}$ & Indicators & $\begin{array}{l}\text { Factor } \\
\text { loading }\end{array}$ & $\begin{array}{l}\text { KMO and } \\
\text { Bartlett's test }(>=0.5)\end{array}$ & $\begin{array}{l}\text { Cronbach's } \\
\text { alpha }(>=0.7)\end{array}$ \\
\hline \multirow[t]{5}{*}{$\overline{\mathrm{ICT}}$} & 5 & ICT1 & 0.745 & 0.8 & 0.789 \\
\hline & & ICT3 & 0.787 & & \\
\hline & & ICT5 & 0.700 & & \\
\hline & & ICT6 & 0.833 & & \\
\hline & & ICT7 & 0.665 & & \\
\hline \multirow[t]{7}{*}{ KS } & 7 & KS1 & 0.682 & 0.805 & 0.8 \\
\hline & & KS2 & 0.594 & & \\
\hline & & KS3 & 0.692 & & \\
\hline & & KS4 & 0.587 & & \\
\hline & & KS5 & 0.745 & & \\
\hline & & KS7 & 0.680 & & \\
\hline & & KS8 & 0.610 & & \\
\hline
\end{tabular}

Table 4 Fitness indexes of the overall model

\begin{tabular}{llll}
\hline Name of the Index & Value obtained & Level of Accepted Fit & Results \\
\hline chi-square value $\left(\chi^{2} / \mathrm{df}\right)$ & 2.773 & Below 3 & Acceptable \\
CFI & 0.901 & Very close to 1 & Acceptable \\
GFI & 0.924 & $>=0.90$ & Acceptable \\
AGFI & 0.910 & $>=0.90$ & Acceptable \\
\hline
\end{tabular}

Factor analysis was performed on the 7 items of ICT and 9 items of KS. In the validation process of factor analysis, two items of ICT (ICT2, ICT4) and two items of KS (KS6, KS9) dropped due to poor factor loadings of less than 0.5. Uni-dimensionality is achieved when the items have acceptable factor loading that is 0.5 or higher (Hair et al. 2006). Table 3 summarizes the results of reliability and validity.

\section{Structural equation modeling (SEM)}

SEM technique has been designed to judge how good a proposed conceptual model can fit the data collected and also to find the structural relationships between the sets of the latent variables. It was adopted to examine the proposed hypothesis on the relationship between ICT, and KS.
The SEM was conducted using Maximum Likelihood Estimation (MLE) procedure. It is one of the most popular methods and is effective when the multivariate normality is used. The final model of the study is illustrated in Figure 1. The curved bi-direction arrow (as shown in Figure 1) represents the covariance or correlation between the indicated pair of measurement errors of the respective items due to redundancy. Therefore, the correlated errors were set to be "free parameter estimates" using the double-headed arrow (Barbara, 2016).

\section{Overall model fit}

The last step is to test the model fit, i.e. to test how best the collected data set fits the research model. To test this, several indicators were computed by using analysis of a moment 
structures (AMOS). The most fundamental measure of overall fit in SEM is the likelihood-ratio chi-square statistics. According to Bagozzi and Yi (1988), a p-value exceeding 0.05 and a normed chisquare value ( $\chi^{2} / \mathrm{df}$ ) that is below 3 , are normally considered as acceptable. Comparative fit index (CFI) values close to 1 indicate a very good fit (Hair et al. 2006). Goodness-of-Fit Index (GFI) value greater than or equal to 0.9 indicates good fit and Adjusted Goodness-of-Fit Index (AGFI) value must be greater than or equal to 0.9 (Bagozzi et al. 1988). The developed model has been proved to meet all the requirements and the results are shown in Table 4. Hence, the model was utilized to test the hypothesized relationships among the constructs.

\section{Testing hypothesis}

The results revealed that ICT has a significant and positive effect $(\beta=0.35$ at $\mathrm{p}=0.001)$ on KS. Therefore $\mathrm{H}_{1}$ was supported and accepted $(\mathrm{p}=0.001)$.

\section{Conclusions}

This paper examined the relationship between knowledge sharing and ICT in Indian agricultural organizations using structural equation modeling method. It found that ICT has a significant and positive effect $(\beta=0.35$ at $p=0.001)$ on the knowledge sharing process in the respondent organizations. Respondent organizations are using ICT tools like computers, laptops, and mobile phones for disseminating and sharing agriculture knowledge with the farm communities. The study found that people like managers, veterinary doctors, and program coordinators in milk co-operatives have been using the Internet, emails for sharing knowledge from state and national research institutes, whereas field supervisor, field technical officers had limited access to the Internet, email, etc.

This study might help the managers of the organizations to understand and to find which type of ICT tools and infrastructure are critically required for an effective knowledge sharing process. Because organizations may not manage all modes of knowledge, they might need robust strategies that involve a network of knowledge partners for sharing knowledge.

The easy access to ICT and the low cost of ICT tools have enhanced development and interest in the field of knowledge sharing in agriculture. Rapid development in the field of ICT like the Internet, emails, Web technologies, video-conference, and rapid mobile penetration contribute to the sharing of knowledge within organizations and with farm communities.

\section{Acknowledgments}

I would like to acknowledge both milk co-operatives, for their cooperation and participation in conducting this study.

\section{References}

Albaum G (1997) The Likert scale revisited. market research society. Journal 39: 1-21

Bagozzi RP, Yi Y (1988) On the evaluation of structural equation models. J Acad Marketing Sci 16: 74-94

Byrne Barbara M (2016) Structural equation modeling with AMOS: basic concepts, applications, and programming: New York: Routledge

Chadha S, Saini R (2014) Information technology support to knowledge management practices: A structural equation modeling approach. IUP J Knowl Manage 12:39-52

Chua A (2004) Knowledge management systems architecture: A bridge between KM consultants and technologies. Int J Inf Manage 24: 8798

Hair JF, Black WC, Babin BJ, Anderson RE, Tatham RL (2006) Multivariate data analysis: Upper Saddle River, NJ: Pearson Prentice Hall.

Kale RB, Rohilla P, Meena M, Wadkar SK (2015) Information and communication technologies for agricultural knowledge management in India. J Glob Comm 8: 16-22

Karadsheh L, Mansour E, Alhawari S, Azar G, El-Bathy N (2009) A theoretical framework for knowledge management process: towards improving knowledge performance. Communications of the IBIMA 7: $67-79$

Kothari D, Kameswari V (2019) Developing a standardized tool for assessing the ICT competence of the agricultural extension personnel. J Appl Natural Sci 11: 352-360

Kukreja A, Chakrabarti B (2013) Agricultural Knowledge Management and Dissemination: Initiatives by Information and Communication Technology. J Global Commun 6: 51-58

Lee YC, Lee SK (2007) Capabilities, processes, and performance of knowledge management: a structural approach. Human Factors Ergonomics in Manuf Serv Ind 17: 21-41

Patil VC, Hugar LB, Priya P, Prabhuraj A, Balaji V, Yaduraju NT (2011) Information and communication technologies for agriculture knowledge management in India. World Appl Sci J 14: 794-802

Rao Rama TP (2010) Dairy Information services kiosk and dairy portal, Working Papers, eSocialSciences, https://EconPapers.repec.org/ RePEc:ess:wpaper:id:3269.

Sasidhar P, Sharma V (2006). Cyber livestock outreach services in India: a model framework. Livest Res Rural Dev 18: 1-12

Sekaran U, Bougie R (2016) Research methods for business: A skill building approach: John Wiley \& Sons

Siong Choy C, Kuan Yew W, Lin, B (2006) Criteria for measuring KM performance outcomes in organisations. Ind Manage Data Syst 106: 917-936

Sunil Rajoria, SKR Virendra Singh, Manisha Singodia, Brijesh Nanda, Harshita Bhumra (2018) Attitude of livestock farmers towards the ICT based livestock extension services in Jaipur District of Rajasthan, India. Int J Curr Microbiol Appl Sci 7: 1014-1021

Thirunavunakkarasu D, Thorne P, Balaji V, Bezkorowajnyj PG, Romney D (2008) Dairy tool box and its relevance to Indian dairy extension system. IN: Prasad, C. and Babu, S. (eds), Social science perspectives in agriculture-a thrust for integration. Proceedings of the International conference on Social perspectives in Agricultural Research and Development IARI, New Delhi, February 15-18, 2006. pp. 505-519.

Venkitachalam K, Bosua R (2014) Roles enabling the mobilization of organizational knowledge. J Knowl Manage 18: 396-410

Yew Wong K (2005) Critical success factors for implementing knowledge management in small and medium enterprises. Ind Manage Data Syst 105: 261-279 